\title{
L2 Learners' expected ideal English as a Second Language (ESL) Teacher
}

\author{
Prasangani K.S.N \\ Department of English Language Teaching, Faculty of Social Sciences and Languages \\ Sabaragamuwa University of Sri Lanka \\ email:nilushikap@yahoo.com
}

DOI: https://doi.org/10.37134/ajelp.vol7.2.2.2019

Cite this article (APA): Prasangani, K. S. N. (2019). L2 Learners' expected ideal English as a Second Language (ESL) Teacher. AJELP: Asian Journal of English Language and Pedagogy, 7(2), 10-17. https://doi.org/10.37134/ajelp.vol7.2.2.2019

\begin{abstract}
This study investigated the expected ideal English as a Second Language (ESL) teacher of the L2 learners in Sri Lanka. ESL teacher is a key person in the ESL classroom in Sri Lanka. School is the primary spot for the vast majority of the L2 students to start their L2 learning in Sri Lanka. This investigation was led among 30 Sri Lankan state funded university students by utilizing the mixed method. There were non-English majors among the participants and participation was voluntary. The questionnaire data were analyzed by utilizing SPSS and group discussion information were analyzed through categorization technique. The results of the questionnaire analysis showed that, L2 students expect their ESL educators to have good skill in using English language, be well prepared, have the capacity to motivate the students and possess great individual characteristics. Furthermore, through the group discussion, it was identified that most of the students lost their inspiration because of the personality and teaching ability of the ESL teacher at school. More significantly, these students feel motivated to begin their L2 learning later because of a motivating ESL instructor either in a tuition center or in an institute. Indeed, the findings recommend that the qualities and ability of the ESL teacher in an L2 classroom are critical in motivating the L2 students in Sri Lanka. These findings can be applied for the advancement of the selection of English Language teachers in Sri Lanka.
\end{abstract}

Keywords: L2 motivation, L2 learners, classroom experiences, ESL teacher, L2 Motivational Self System

\section{INTRODUCTION}

Motivation is a key factor in learning English as a second language (ESL). ESL motivation depends on the learners' ideal L2 self (future vision), ought to L2 self (compulsory obligations) and L2 learning experiences (Dornyei, 2009). Learners' ideal L2 self was recognized as the key factor of motivating English learning among the Sri Lankan university students (Prasangani \& Nadarajan, 2015) and Malaysian university students (Prasangani, 2014a). Anyhow, some L2 motivational studies in the Asian context proved the learning experiences as the key factor of L2 motivation (Islam, Lamb, \& Chambers, 2013; Lamb, 
2012; You \& Dornyei, 2014; Shahbaz, Islam, \& Malik, 2017). More importantly, motivation studies conducted among the secondary students proved the key contribution of learning experiences on the L2 motivation. In such contexts ESL teacher's role is significant, because up to now most of the ESL learners in Asian contexts start their L2 learning in schools. Thus, this study examined Sri Lankan L2 learners' perspective on their L2 teachers.

\section{BACKGROUND OF THE STUDY}

Sri Lankan educational policies were designed to reach wholistic and sustainable development of Sri Lanka (National Report, 2004). In Sri Lankan education system learning English as a second language has been given a prominent place since the British colonial period onwards. According to the recent changes, Sri Lankan formal English education begins from primary school. There are three key stages in primary English learning. Key stage I (Grade 1 and 2) allows students to learn English in a stress free environment by playing without doing any desk work. In Key stage II (Grade 3 and 4) students are allowed to do desk work and play. Key stage III is mostly allocated for the desk work (National Institute of Education, 2000). Junior secondary students start learning English as a second language from Grade 6 and they expect to sit General Certificate Examination of Ordinary Level (G.C.E. O/L) in Grade 11. They have to sit for General English paper in General Certificate Examination of Advanced Level (G.C.E. A/L) in Grade 13 (National Report, 2004).

Bilingual education was introduced to the government schools in 2001. The purpose of this program is to use English as a tool for thinking with a global mind while protecting and caring for the local languages and cultural identity (Algama, 2009). Bilingual education from Grade 6 was implemented under the adapted circular No. 05/2007 on 02.03.2007 (NIE, 2007). English is considered as the second language in the curriculum and also considered as the link language of the country by the 13th amendment to the constitution (Prasangani, 2014b).

A new program of English as a Life Skill was initiated in 2009. It emphasized the importance of English and IT for the education of Sri Lanka. The main objective of the program was to teach English in an understandable way to use it without fear and reluctance. Communicative competence was given the priority in the program due to the prevalence need of communicative competence of the students especially in rural areas of Sri Lanka.

In fact, English has been given a significant place in the Sri Lankan education system. However, in rural schools, students suffer due to the lack of physical and human resources. This leads to the problematic condition for mastery of English in rural areas (UNICEF, 2013). According to the Ministry of Education, rural schools belonged to the "uncongenial" or "very uncongenial" condition due to the scarcity of human and physical resources (Ministry of Education, 2013). Lack of teachers made these learners more vulnerable (Davis, 2015; Liyanage, 2014). In addition, some of the English teachers in the schools are not well-trained English teachers. This context is similar to the neighboring South Asian country, India (Sarwal \& Lamb, 2018). Within this context gaining the adequate English proficiency for the rural learners is very difficult.

Sarwal and Lamb, (2018) highlighted the importance of examining the role of English teacher to ESL learners' motivation, because teachers inspire the ESL learners.

Dornyei (2001) introduced motivational strategies for the L2 classrooms. According to him these strategies are techniques to direct students to a goal directed learning path. ESL teacher is the principal partner of these strategies. In motivational teaching practice, firstly teacher needs to create basic motivational conditions (e.g. good relationship with the students, and pleasant supportive environment), secondly generates the initial classroom motivation (e.g. 
enhancing L2 related values and attitudes), thirdly maintains and protects the motivation in class (e.g. make learning enjoyable), and finally encourages positive retrospective selfevaluation (e.g. providing motivational feedback).

Bowman (2011) stated that the classroom teachers should facilitate the three human needs of autonomy (freedom for choices and determine the future), mastery (ability to learn and expertise), and purpose (search for the use of learning to the life). Several studies were conducted to examine the ESL teachers' role on the motivation of the ESL learners. Lamb \& Wedell (2013), Sarwal \& Lamb (2018) conducted a study on teachers' significant role in inspiring and motivating the ESL learners in Indonesia, China, and India. According to the findings these learners focuses specifically on the teaching methodology. Indian and Chinese learners are specific about the pedagogy, but the Indonesian learners wanted to have fun and lively classroom environment. In terms of teacher's professional quality Indian learners highly expect the fluency and competency of the teachers. On the other hand, Chinese learners expect dedicated and hardworking teacher.

In relation to the personal qualities, Indian learners expect kind, nice, easy going and young teachers while Indonesian and Chinese learners are not very much concern on the personal qualities. Indian learners mentioned that their teachers made the feeling of learning English easy and they built their confidence. It is unique for the Indian learners that their teacher improved their image or self-respect. These studies further examined the actions taken by the students through the motivation and inspiration of the teachers. All the learners focused on learning English at home, private institutes or in their environment. Many of the Indonesians, started to use media like TV programs, music and songs. It is evident that Indian teachers inspire the learners to practice the language.

Indonesian and Chinese learners favored to practice their speaking skill and Indian learners favored to improve reading, writing and pronunciation. Shishavan, (2009) and Zamani \& Ahangari (2016) stated that Iranian learners expect the teacher to have good proficiency of English, good knowledge of pedagogy and methodology, good personality, ability to develop confidence and proper relationships with students as well as maintain disciplines in the classroom.

In accordance with the recent literature, it is evident that ESL teachers paly a dominant role in the Asian ESL learners' English language learning. In fact, this study expects to uncover the Sri Lankan ESL learners' perspective on the ESL teachers through the following research questions.

1. What are the qualities that learners expect from the ESL teachers in Sri Lanka?

2. How teachers' qualities motivate the learners to learn L2 in the real classroom?

\section{METHODOLOGY}

Participants of the current study were Sri Lankan non English major undergraduates $(n=30)$ and aged between $22-25$ years. The questionnaire for the study was adapted from Lamb \& Wedell (2013). The pilot study was conducted for 46 items and the internal consistency of the instrument was 0.89 . The score was above 0.7 and it showed reliability of the questionnaire (Pallant, 2007).

The majority of the participants were females (93\%) and all of their mother tongue was Sinhala. Present study used the descriptive analysis for the questionnaire data analysis and group discussion data were analyzed through categorization technique. 
Table 1: Demographic Profile of the Participants

\begin{tabular}{lll}
\hline \multirow{2}{*}{ Gender } & Male & $7 \%$ \\
\cline { 2 - 3 } & Female & $93 \%$ \\
\hline Mother Tongue & Sinhala & $100 \%$
\end{tabular}

\section{RESULTS AND DISCUSSION}

\section{Expected Qualities of an ESL Teacher}

Table 2 shows the expected qualities of an ESL teacher in Sri Lanka. In accordance with the data, it is evident that Sri Lankan ESL learners expect high quality professional teachers with good skill in reading, writing, speaking and considerable knowledge about grammar. Further, it is noted that these learners do not expect their teachers to know about the English culture well. Similar finding is reported among Indian learners (Sarwal \& Lamb, 2018) because both groups are from similar ESL contexts in contrast to the Chinese and Indonesian learners (Lamb \& Wedell, 2013) who belong to the EFL contexts. In addition, English has been given a greater importance in the education and society of Sri Lanka from the British colonial period onwards (Prasangani, 2018a). In such context, the English language teachers become the role models of the learners. Thus, policy developers should consider the matter when preparing English teachers for the education system.

Sri Lankan learners concern about the teaching methodology of the teachers. According to the data they expected highly trained teachers to teach English in Sri Lanka. They were not concerned about the syllabus and homework. This might be because most of the learners were not happy with the syllabus presented by the Sri Lankan English education, because the materials used in teaching are not authentic and they are alien to most of the students (Meyler, 2015).

Table 2: Expected Teacher Qualities

\begin{tabular}{lll}
\hline Quality & Sub Categories & \% \\
\hline Professional Qualities & Speak in English well & $99 \%$ \\
\cline { 2 - 3 } & Writing skill & $99 \%$ \\
\cline { 2 - 3 } & English reading skill & $96 \%$ \\
\cline { 2 - 3 } & Good English pronunciation & $99 \%$ \\
\cline { 2 - 3 } & Have sound vocabulary & $99 \%$ \\
\cline { 2 - 3 } & Knowing English culture & $70 \%$ \\
\cline { 2 - 3 } & Well known about grammar & $95 \%$ \\
\hline Teaching Methods & Preparation for the lessons & $90 \%$ \\
\cline { 2 - 2 } & Use techniques & $90 \%$ \\
\hline
\end{tabular}




\begin{tabular}{|c|c|c|}
\hline & Follow syllabus & $75 \%$ \\
\hline & Manage the time & $90 \%$ \\
\hline & Assign homework & $70 \%$ \\
\hline & Group activities & $90 \%$ \\
\hline & Use recent technology & $90 \%$ \\
\hline & Promote self-learning & $90 \%$ \\
\hline & Use lesson plans & $90 \%$ \\
\hline & Focus on weak learners & $90 \%$ \\
\hline & Classroom management & $90 \%$ \\
\hline & Teach English in English & $90 \%$ \\
\hline & Teach English in Sinhala & $10 \%$ \\
\hline Personal Qualities & Neat and tidy & $90 \%$ \\
\hline & Polite and respect to the students & $90 \%$ \\
\hline & Well disciplined & $90 \%$ \\
\hline & Punctual & $90 \%$ \\
\hline & Flexible & $90 \%$ \\
\hline & Open & $90 \%$ \\
\hline & Interested about teaching & $90 \%$ \\
\hline & Assess the own work & $90 \%$ \\
\hline Motivation & Available for the students & $90 \%$ \\
\hline & Allow students to use English & $90 \%$ \\
\hline & Assess students with reasonable feedback & $90 \%$ \\
\hline & $\begin{array}{l}\text { Helpful for students in and outside of the } \\
\text { classroom }\end{array}$ & $90 \%$ \\
\hline & Friendly & $90 \%$ \\
\hline & Sense of humour & $70 \%$ \\
\hline & Treat students fairly & $90 \%$ \\
\hline & Motivate English learning & $95 \%$ \\
\hline
\end{tabular}


More importantly, students expect the teachers to teach English in English. This may be due to the prevalent need of English in Sri Lanka. Sri Lankan learners expect high personal qualities from the teachers as Indian learners. This area needs to be addressed through the persona; development workshops or training. It is important to encourage teachers' development through the professional trainings.

In relation to the teacher's contribution to learners' motivation, students expect a great support from the teachers to motivate their learning. In accordance with the data, it is visible that Sri Lankan learners expect very close relationship with the teachers. This finding is different from the Indonesian, Chinese, and Indian learners. They do not expect a very close relationship with the teachers. This teacher student relationship can be created through learner centered activities, because teacher should always guide and facilitate the students.

Sri Lankan learners are similar to Chinese and Indian learners with reference to expecting interesting classrooms rather than a funny classroom (Sarwal \& Lamb, 2018). This suggests that learners need lively classroom with positive learning experiences.

\section{How teachers' qualities motivate the learners to learn $L 2$ in the real classroom?}

This section discusses the results of the group discussions. Through the group discussions participants explained their real-life experiences in relation to their English language learning during the school time.

\section{Learner 1}

She was an amazing teacher. I was inspired through her teaching and personality. Every day, I went to her class because I loved her way of teaching. She became the role model of my life. I still want to be a teacher like her.

\section{Learner 2}

She was a Burgher teacher. She had a very nice accent and she was really competent in teaching English. I went her tuition from my childhood. I improved my English from her.

\section{Learner 3}

I loved his teaching, because he tried to give us something new always. He brought extra things to the class. He assigned some homework. Really, he motivated me to learn English.

In relation to the learners' comments about their English teachers, it is clear that the teacher has a great role in the ESL learners' learning. Learners were inspired through the personality, teaching methods, proficiency and dedication. This initial motivation motivates them to learn English well.

Some learners emphasized the problematic conditions of the competency of the English teachers in the schools.

\section{Learner 4}

Most of our teachers were English medium graduates and they did not have proper training to teach English. Not only that they used mother tongue in teaching English. 
ESL teaching needs proper training. In Sri Lankan context especially in rural areas there are few ESL teachers due to the lack of facilities in these areas (Prasangani, 2018b). In fact, other subject teachers were recruited as ESL teachers without considering their qualifications. This has become a serious issue in learners' learning, because they may not achieve the required proficiency ( Samaranayake, 2016) and they will be demotivated. This is very important insight for the education policy developers, because this finding highlights the need of standardizing English teacher recruitments.

With reference to the teaching methods, most of the learners emphasized the teachers' special focus on the given text books and clever students.

\section{Learner 5}

Our teachers tried to complete the syllabus. They worked with the fluent students and weaker ones were neglected. Some teachers called the fluent ones to the front and continued the lesson with them. So, we use to cut the English lesson.

Due to the unfamiliar context of the text books, most of the Sri Lankan ESL learners face difficulties in learning English. In this situation, if they do not get enough support and motivation from the teacher, they will be demotivated in learning English. In Sri Lanka, most of the ESL learners start their English learning from schooling years. At this stage, teacher support and motivation are essential for their learning.

\section{Learner 6}

I can remember one incident when I was in grade 3. My English teacher threw away my homework by complaining. I was very upset, because I spent lot of time for that work. That made me demotivate in learning English.

This clearly emphasizes the gap between learner's expectation and the real classroom context. Learners expect friendly, motivating and flexible teachers, but in the actual classroom they meet the opposite. Teachers' negative attitudes and harassments demotivate the learners (UNICEF, 2013).

\section{CONCLUSION AND RECOMMENDATION}

This study investigated critical role of the ESL teacher to motivate the ESL learners in Sri Lanka. It is evident that Sri Lankan ESL learners expect highly professional and trained ESL teachers with good personal qualities and ability to motivate the learners. This has become a reality in some learners' lives, but in most cases, there is a big gap between the expectations and the reality. This has implicated the English learning motivation of the learners in Sri Lanka. These findings must be considered cautiously due to the small sample size. Policy makers can consider the findings as remarkable hints to prepare the education policies of English language teaching and learning. They should try to minimize the gap between the learner expectations and the real classroom situation. Proper training, recruitments, and revisions in the English curriculum to promote learning can be identified as the necessary steps to minimize the gap between the expectations and the reality. 


\section{REFERENCES}

Bowman, R. (2011). Rethinking What Motivates and Inspires Students. The Clearing House: A Journal of Educational Strategies, Issues and Ideas, 84(6), 264-269. https://doi.org/10.1080/00098655.2011.592164

Dornyei, Z. (2001). Motivational Strategies in the Language Classroom. Cambridge: Cambridge University Press. https://doi.org/10.1016/S0889-4906(02)00009-1

D"ornyei, Z. (2009). The L2 Motivational Self System.In Z. D"ornyei \& E. Ushioda (Eds.), Motivation, Language Identity and the L2 self (pp.9-42). Bristol,UK: Multilingual Matters.

Islam, M., Lamb, M., \& Chambers, G. (2013). The L2 Motivational Self System and National Interest: A Pakistani perspective. System, 41(2), 231-244, https://doi.org/10.1016/j.system.2013.01.025

Lamb, M. (2012). A Self System Perspective on Young Adolescents Motivation to Learn English in Urban and Rural Settings. Language Learning, 62(4), 997-1023. https://doi.org/10.1111/j.14679922.2012.00719.x

Lamb, M., \& Wedell, M. (2013). Inspiring English teachers: a comparative study of learner perceptions of inspirational teaching. ELT Reserach Papers. London. https://doi.org/978-0-86355-709-5

Pallant, J. (2007). SPSS Survival Manual : A Step by Step Guid to Data Analysis using SPSS for Windows. Berkshire: Open University Press.

National Report (2004). Colombo: Ministry of Education

National Institute of Education. (2000). English language syllabus for grades 3, 4, 5. Maharagama:NIE

National Institute of Education (2007).Islandwide Needs Survey on Bilingual Education.Maharagama, Sri Lanka.

Meyler (2015). Sri Lankan English: An appropriate model for the teaching of English in Sri Lanka? In H. Coleman (Eds.), Language and Social Cohesion in the Developing World (pp. 178-185), Colombo: British Council and GIZ.

Prasangani, K. . S. N. (2014a). Malaysian L2 Learners' English Learning Motivation: A Study of Goals, Attitudes and Self. Issues in Language Studies 3 (1), 23-35.

Prasangani, K. S. N. (2014b). Overview of Changes in the Sri Lankan English Education System: From the Colonial Era to Present Day Sri Lanka. Modern Research Studies, 1(2), 193-202.

Prasangani, K. S. N. (2018a). English Language Education in Sri Lanka Link with the Learners' Motivational Factors. Humanising Language Teaching, (August), 1-11.

Prasangani, K. S. N. (2018b). Investigation of L2 Motivational Self System: A Comparative Study of Undergraduates from Displaced and Resettled Regions in Sri Lanka. Sabaragamuwa University Journal, 16(1), 58-67.

Prasangani, K. S. N., \& Nadarajan, S. (2015). Sri Lankan Urban and Rural Undergraduates ' Motivation to Learn English. International Journal of Technical Research and Applications, (18), 26-33.

Sarwal, A., \& Lamb, M. (2018). Learner perceptions of inspiring English teachers in nothern India. In Explorations : Teaching and Learning English in India (pp. 20-30). Kolkata: British Council.

Shahbaz, M., Islam, M., \& Malik, M. A. (2017). Role of Gender Differences and Parents 'Education in Shaping L2 Motivation of Pakistani Students. Journal Of Research and Reflections in Education, 2, 210-223.

Shishavan, K. S. \& H. B. (2009). Characteristics of an Effective Teacher as Percived by Iranian Teachers and Learners of Englidh. Journal of Education and Learning, 2(4), 130-143.

UNICEF. (2013). Country Study: Out of School Children in Sri Lanka. Colombo.

W. Samaranayake, S. (2016). Oral Competency of ESL/EFL Learners in Sri Lankan Rural School Context. SAGE, April-June, 1-10. https://doi.org/10.1177/2158244016654202

You, C., \& Dornyei, Z. (2014). Language Learning Motivation in China: Results of a Large-Scale Stratified Survey. Applied Linguistics, 1-26. https://doi.org/10.1093/applin/amu046

Zamani, R., \& Ahangari, S. (2016). Characteristics of an effective english language teacher (EELT) as perceived by learners of English. International Journal of Foreign Language Teaching \& Research, 4(14), 69-87. 